\title{
Causal learning is collaborative: Examining explanation and exploration in social contexts
}

\author{
Cristine H. Legare $^{1} \cdot$ David M. Sobel $^{2} \cdot$ Maureen Callanan $^{3}$
}

Published online: 25 July 2017

(C) Psychonomic Society, Inc. 2017

\begin{abstract}
Causal learning in childhood is a dynamic and collaborative process of explanation and exploration within complex physical and social environments. Understanding how children learn causal knowledge requires examining how they update beliefs about the world given novel information and studying the processes by which children learn in collaboration with caregivers, educators, and peers. The objective of this article is to review evidence for how children learn causal knowledge by explaining and exploring in collaboration with others. We review three examples of causal learning in social contexts, which elucidate how interaction with others influences causal learning. First, we consider children's explanation-seeking behaviors in the form of "why" questions. Second, we examine parents' elaboration of meaning about causal relations. Finally, we consider parents' interactive styles with children during free play, which constrains how children explore. We propose that the best way to understand children's causal learning in social context is to combine results from laboratory and natural interactive informal learning environments.
\end{abstract}

Keywords Causal reasoning - Cognitive development .

Culture $\cdot$ Informal learning environments

Children actively seek to understand the causal structure of the world around them. Causal learning in childhood is a dynamic

Cristine H. Legare

legare@austin.utexas.edu

1 The University of Texas at Austin, Austin, USA

2 Brown University, Providence, USA

3 University of California, Santa Cruz, Santa Cruz, USA process of observation, explanation, and exploration within complex physical and social environments. Children's learning is not exclusively the product of processing information individually; instead, learning is inextricably embedded in social activities and practices (Cole, 1996, 2010; Gauvain \& Perez, 2015; Rogoff, 2003; Vygotsky, 1962). Understanding how children learn causal knowledge requires examining how they update beliefs about the world given novel information and studying the processes by which children learn in collaboration with caregivers, educators, and peers.

The objective of this article is to review evidence for how children learn causal knowledge by explaining and exploring in collaboration with others. For the purposes of this review, we constrain explaining to the ways in which children elicit and generate verbal information about a set of causal relations and exploring to the ways in which children act on the world that generates information from others or the environment. We propose that explaining and exploring operate synergistically: Explanation serves as a mechanism for generating, constraining, and evaluating hypotheses (Legare \& Lombrozo, 2014; Walker, Lombrozo, Legare, \& Gopnik, 2014). Exploration serves as a mechanism for testing those hypotheses or for discovering that there is something to explain (Legare, 2014). These two processes allow children to build more sophisticated and veridical representations of the causal structure of the world around them.

Originally proposed by Vygotsky (1962), sociocultural theory contextualizes children's cognitive development (Cole, 2010; Gauvain, 2001; Lancy, Bock, \& Gaskins, 2010; Rogoff, 1990; Tudge, Putnam, \& Valsiner, 1991; Wertsch \& Tulviste, 1992). The development and socialization of the child is an interactive process in which the young child is exposed to and active in "a community of those who share his sense of belonging to a culture" (Bruner, 1986, p. 127), creating a connection between a child's social context and 
development. Parents, adult caregivers, and peers are present and active partners in children's learning processes (Bjorklund, Hubertz, \& Reubens, 2004; Callanan, Siegel, \& Luce, 2007; Goodnow \& Collins, 1990 Lancy, 2008; Lave \& Wegner, 1991).

Given the active role of caregivers in children's development (Callanan \& Jipson, 2001), understanding the development of causal learning requires examining caregiver scaffolding and socialization (Geary \& Bjorklund, 2000; Harkness \& Super, 1996; Keller, Voelker \& Yovsi, 2005; Okagaki \& Divecha, 1993). Children acquire new skills and behaviors with the aid of more competent cultural members who scaffold their learning and allow children to attain skills that are just beyond their present abilities (Vygotsky, 1962).

Examining children's cognitive development within complex social and physical contexts provides insight into their developing abilities and competencies. Children who may not be able to demonstrate the capacity to engage in a behavior of interest in a novel environment may show a mastery of the same skill in familiar environments. For example, Carraher, Carraher, and Schliemann (1985) describe this contrast when examining Brazilian street vendors use of complex mathematical techniques. Children who did not engage in higher order mathematical thinking when presented with noncontextualized math problems generated accurate solutions when they were given the same problems within the familiar context of selling merchandise.

\section{Causal learning in context: Three examples}

To understand the importance of explaining and exploring for causal learning, it is imperative to attend to the social and cultural contexts in which these activities take place. Cultures differ dramatically along a number of dimensions that are relevant to understanding parent-child interaction (Legare \& Harris, 2016; Nielsen, Haun, Kärtner, \& Legare, 2017). These differences include cultural values (e.g., competition, conformity, cooperation, creativity, independence), primary caregivers (e.g., parental vs. extended family and siblings), language (e.g., the ways in which different languages afford requests for information or describe evidentials), pedagogical style (e.g., didactic teaching vs. expectation of observational modeling), and parenting style (e.g., child-centered vs. adult-centered; Bolin, 2006; Clegg \& Legare, 2017; Clegg, Wen, \& Legare, 2017; Cole, 1990; Gaskins \& Paradise, 2010; Keller, 2007). While reviewing all of these cultural differences is beyond the scope of this review, we review three examples of causal learning in social contexts, which elucidate how interaction with others influences causal learning. First, we consider children's explanation-seeking behaviors in the form of "why" questions. Second, we examine parents" elaboration of meaning about causal relations. Finally, we consider parents' interactive styles with children during free play, which constrains how children explore.

\section{"Why" questions}

Children do not learn causal knowledge only through observation and solitary interaction with the world (e.g., Harris \& Koenig, 2006; Harris, Pasquini, Duke, Asscher, \& Pons, 2006). Instead, children actively seek out information from others. Examining children's "why" questions provides unique insight into how children seek out causal information from more experienced members of their family and community. Research on children's "why" questions has revealed a great deal about the developmental course of children's requests for explanation, and about how children use these questions to gain better understanding of causal mechanisms. Hood and Bloom (1979) showed that by 30 months, children are productively using causal statements and "why" questions. In a diary study, Callanan and Oakes (1992) similarly found that parents of 3-through 5-year-olds reported their children's spontaneous use of meaningful "why" questions in conversation. Frazier, Gelman, and Wellman (2009) provided clear evidence that these questions are likely to be genuine requests for causal explanations rather than merely bids to keep conversation going. These children were more likely to continue to ask versions of the same question when given a nonexplanatory reply but were more likely to ask a new follow-up question when given an explanatory answer.

Notably, there are individual differences in the extent to which caregivers and educators encourage explanatory behavior on the part of the child, which may potentially influence the amount of explanatory behavior children generate, and in turn what children learn (Clegg \& Legare, 2017). The extent to which the use of "why" questions is culturally variable, however, is contentious. Tizard, Hughes, Carmichael, and Pinkerton (1983) found that a group of 4-year-old girls in the UK asked more explanatory questions at home than at school, and that this difference was more pronounced for working-class girls. In a study of Mexican-heritage families of diverse schooling backgrounds living in the U.S., children asked as many "why" questions as the middle-income children in the Callanan and Oakes (1992) study (Solis \& Callanan, 2016). This included two groups of Mexican immigrant families, one group in which parents had an average of 7 years of schooling and held working-class or migrant jobs, and one group in which parents had completed at least 12 years of schooling. Children in these immigrant families asked as many questions, and even many of the same questions, as middle-income European American children.

In contrast, Gauvain, Munroe, and Beebe (2013) reported cultural differences in children's "why" questions. They analyzed archival language data from four non-Western cultural 
communities collected in the late 1970s and found that while information-seeking questions were asked as often as in Western communities, the subset of explanation-seeking questions were asked much less often. While the methods used in the Gauvain et al. (2013) study are quite different from those of the other studies cited, their findings raise important questions about cultural diversity in practices such as asking "why" questions.

"Why" questions constitute a social practice of inquiry about causes and effects in everyday settings that seem to be part of life for many young children. Unlike many laboratory settings, children's spontaneous questions provide unique insight into the aspects of the world around them for which children seek causal explanations.

\section{Elaborating parent-child talk for causal learning}

Children's explanations reveal their causal knowledge (Hickling \& Wellman, 2001; Keil \& Wilson, 2000; Legare, Wellman, \& Gelman, 2009; Sobel, 2004; Wellman \& Liu, 2007). The process of generating explanations assists children in interpreting observed data (E. B. Bonawitz, van Schijndel, Friel, \& Schulz, 2012). Generating explanations facilitates children's acquisition of knowledge or novel inference across a variety of learning environments (Amsterlaw \& Wellman, 2006; Chi, 2000; Chi, DeLeeuw, Chiu, \& LaVancher, 1994; Crowley \& Siegler, 1999; Legare \& Lombrozo, 2014; RittleJohnson, Saylor, \& Swygert, 2008). Such processes are critical for constructing knowledge (Cimpian \& Petro, 2014; Keil, 2006; Wellman, 2011). Indeed, some have even gone so far as to argue that the desire to generate explanations is the motivating force behind all forms of learning (e.g., Brewer, Chinn, \& Samarapungavan, 1998; Gopnik, 1998). Explaining also allows children to articulate new hypotheses for events that might be different from their current state of knowledge (Legare \& Gelman, 2014; Legare, Gelman, \& Wellman, 2010; Walker, Lombrozo, Williams, Rafferty, \& Gopnik, 2017). Encouraging children to explain inconsistency may serve as a critical mechanism for integrating and reconciling discordant or ambiguous information with existing theories and may reduce engagement in theory-preserving strategies like ignoring discordant data (Legare, 2012, 2014).

Like children, parents generate a substantial amount of causal language. There is a large body of work suggesting that the "elaborativeness" of parents' talk with their children is correlated with children's recall of events (Fivush, Haden, \& Reese, 2006). Fivush and her colleagues initially defined elaborative talk with regard to elaborations in narrative reminiscing. More recently, Haden and her colleagues define elaborative talk about science topics in museum contexts as involving the use of wh- questions and associations with prior experiences or knowledge (e.g., Benjamin, Haden, \& Wilkerson, 2010; Haden, 2010; Jant, Haden, Uttal, \& Babcock, 2014).
Elaborativeness in parent talk has been found to correlate with children's memory as well as with their understanding of science-related content, particularly specific kinds of physical causal relations. While not the same as causal explanation, elaborative talk also provides a framing for children's experiences.

Other studies of parent-child explanatory conversations in museum settings suggest that parents' explanations can provide framing that may give children different ways to interpret the activities that they are engaged in (e.g., Crowley, Callanan, Tenenbaum, \& Allen, 2001; Tare, French, Frazier, Diamond, \& Evans, 2011). Fender and Crowley (2007) found that children whose parents explained to them were more likely to develop a conceptual understanding of a museum exhibit than children whose parents did not provide any explanation.

There is also substantial cultural variation in such parentchild interaction. Parents with varied schooling background or attitudes about the nature of knowledge tend to talk differently to their children (Luce, Callanan, \& Smilovic, 2013; Valle, 2006). For example, Valle (2006) found that parents from engineering and science backgrounds focused more on scientific evidence about conflicting claims on topics such as climate change than did parents from other backgrounds. In museum settings, visitors' agendas have been found to correlate with their learning (Falk, Moussouri, \& Coulson, 1998). Tenenbaum and Callanan (2008) showed that Mexican immigrant parents generated fewer explanations than Mexican American parents in a museum setting, and yet the two groups explained equally in a museum-like task at home. Such a difference potentially reflects the novelty of the museum setting for the immigrant families (many of whom had never been to a museum before). All of these factors can contribute to the way in which children generate their own explanations, as they indicate different cultural norms that might encourage different forms of explaining.

\section{Parent-child exploration}

Much in the same way children ask "why" questions to solicit information out of others, they interact with others as a way of gathering more information about the world. Such information allows children not only to learn about specific causal relations but also to coconstruct meaning and be more part of a culture. Exploration then can be seen as the attempt to acquire new knowledge or promote new social interaction through action on the environment. Thus, exploration should not be studied exclusively in the context of solo learning.

There is evidence that children in the U.S. explore for longer periods of time when given ambiguous evidence (E. B. Bonawitz et al., 2010; Gweon, Pelton, Konopka, \& Schulz, 2014; Jara-Ettinger, Gweon, Tenenbaum, \& Schulz, 2015; Stahl \& Feigensen, 2015). These children also explore more systematically when faced with uncertain causal relations as 
opposed to deterministic ones (Cook, Goodman \& Schulz, 2011; Schulz \& Bonawitz, 2007). Exploration might be a way of collecting evidence about ambiguous or more complex hypotheses so that children can better understand the world.

Research with adults (Lagnado \& Sloman, 2004; Sobel \& Kushnir, 2006) and children demonstrates that we may learn more effectively from observing the results of the efficacy of our own actions as opposed to observing others generate the same data in a guided, structured environment (Baldwin, Markman, \& Melartin, 1993; Bonawitz et al., 2012; Gerson \& Woodward, 2014; Kushnir \& Gopnik, 2005; Needham, 2009; Schulz, Gopnik, \& Glymour, 2007). The benefits of learning from one's own actions are most prominent when children discover novel information, as opposed to observing efficacy they have already seen (Sobel \& Sommerville, 2010; Sommerville, Woodward, \& Needham, 2005). This learning benefit may be due to having access to the rationales behind one's actions. When given those rationales, preschoolers learn effectively from others' actions (Sobel \& Sommerville, 2009).

This kind of exploratory behavior is also related to discovery learning. Bruner (1961) emphasized that students who discover information for themselves are more motivated to achieve educational goals and more likely to remember learned information. Students learn better by discovering causal structure through guided activity-based exercises rather than being directly told what to do or being given unstructured activity (Bredderman, 1983; Kittel, 1957; Shulman \& Keislar, 1968). The former type of activity allows children to learn novel information based on scaffolding activities from others (particularly teachers) instead of simply being told information without context or direction. Neither guided exploration nor direct instruction is socially independent, but there is also evidence that free, unguided exploration is potentially less effective than either (Mayer, 2004). Particularly for young children, exploratory play may be a crucial context for cognitive development (Singer, Golinkoff, \& Hirsh-Pasek, 2006; Weisberg, Hirsh-Pasek, Golinkoff, Kittredge, \& Klahr, 2016).

All of these results point to the importance of collaborative exploration for learning. In informal learning environments, some research has shown that the ways that children explore their environment can be influenced in subtle ways by the presence of and the actions of other people. For example, in a study of parent-child engagement at a museum exhibit (a zoetrope), Crowley, Callanan, Jipson et al. (2001) found that when parents were present, children were more likely to engage in exploration of all of the relevant components of the exhibit. Parents seemed to guide their children's exploration in subtle ways that led to better understanding of the phenomenon. Other research has investigated the ways that parents influence their children's exploration in different types of museum exhibits (Fung \& Callanan, 2013; Van Schijndel, Franse, \& Raijmakers, 2010). These findings seem relevant to the recent work showing that guided play leads to better learning than open-ended play
(Weisberg, Hirsh-Pasek, \& Golinkoff, 2013). As with most of the previous research on this topic, the families studied were from largely middle-income European American backgrounds, so it is important to avoid assumptions about this style of interaction being normative (Rogoff, 2003).

Indeed, there is cultural variation in parents' styles of interacting with children. Whereas middle-class U.S. mothers use a great deal of verbal explanation with their children, mothers from rural Guatemala and Mexico expect their children to learn through nonverbal means, including keen observation (Silva, Correa-Chávez, \& Rogoff, 2010). Parents' engagement with exploration and play varies across cultures as well (Gaskins, 2008), and their definitions of play contrast with those of experts (Fisher, Hirsh-Pasek, Golinkoff, \& Gryfe, 2008). Gaskins (2008) explored parents' "ethnotheories" about play and found that European American, African American, and Latino parents varied considerably in their views about whether play is important for learning and whether parents should play with their children; these views also related to how parents engaged with children in the museum setting. One must go beyond studying Western middleclass populations because the same situation may hold different meaning for families from diverse cultural communities (Gaskins, 2008). Future research is needed to examine the extent to which children's causal learning differs based on cultural variation in parent-child interaction.

\section{Conclusions and future directions}

Informal learning environments, such as children's museums and science centers, provide a unique opportunity to study the social context of children's explanation and exploration (Sobel \& Jipson, 2016). Data from laboratory-based studies have demonstrated that young children have sophisticated capacities to both explain and explore; however, the extent to which these capacities translate to such informal learning environments is understudied. For example, the literature examining children's scientific reasoning suggests that preschoolers do not consistently engage in systematic hypothesis testing, nor do they demonstrate consistent understanding of the relation between data and conclusions or how to design unconfounded tests of causal relations (Dean \& Kuhn, 2007; Klahr \& Nigam, 2004; Schauble, 1996). Those who create and study informal learning environments often focus on creating openended activities where children and adults can explore scientific understandings through hands-on exploring and collaborative construction of explanations (Allen, 2004; Gutwill \& Allen, 2010). Cultural differences are also crucial to investigate here for the same reason as above, as families from different backgrounds might approach open-ended activities quite differently, which may support multiple different pathways to causal learning. 
More research is needed to examine how children from diverse cultural backgrounds learn causal knowledge from museum exhibits and other activities. Parents' science explanations predict certain aspects of children's causal learning (Fender \& Crowley, 2007), but such findings need to be expanded to more diverse cultural groups and replicated and extended to other contexts. Future research should also systematically consider variation in the conditions under which parents from different cultural backgrounds choose to encourage children's scientific reasoning, a topic of inquiry with major implications for communities currently underrepresented in STEM fields. These cultural differences might promote different attitudes within children for explaining and exploring, which in turn may foster different avenues for causal learning.

Understanding how children engage in causal learning through explaining and exploring does not just involve the act of children processing data from the environment and integrating that information with their prior knowledge. Children are influenced by the context in which information is presented and the communicative acts parents, teachers, and peers use to convey information, all of which are culturally mediated (Callanan, Shrager, \& Moore, 1995). For researchers in children's causal learning who have argued for "rational constructivism," such cultural influences could be seen as "priors" - pieces of prior knowledge that constrain hypotheses and inferences (Xu \& Kushnir, 2012). But this is an obviously unsatisfying explanation. Priors are fixed, while the contextual and cultural influences we have described are dynamic. Moreover, priors are based on the individual - children as learners - as opposed to the idea that children construct meaning from their interactions and the nature of that construction is different depending on individual variations in interactive style.

We propose that the best way to understand children's causal learning is to combine results from laboratory and natural interactive environments. Conducting research in informal learning settings (like museums) is not a replacement for research done in the lab but instead, provides unique insight into the social context of children's learning because they are natural learning spaces for many families (Callanan, 2012; Callanan, Martin, \& Luce, 2016; Legare, Gose, \& Guess, 2016; Sobel, Letourneau, \& Meisner, 2016). There are challenges in tackling the complexity of this work; however, our experience is that working through these challenges has great potential to lead us toward a more comprehensive understanding of children's causal learning.

\section{References}

Allen, S. (2004). Designs for learning: Studying science museum exhibits that do more than entertain. Science Education, 88, S17-S33.
Amsterlaw, J., \& Wellman, H. M. (2006). Theories of mind in transition: A microgenetic study of the development of false belief understanding. Journal of Cognition and Development, 7(2), 139-172.

Baldwin, D., Markman, E., \& Melartin, R. (1993). Infants' ability to draw inferences about nonobvious object properties: Evidence from exploratory play. Child Development, 64, 711-728.

Benjamin, N., Haden, C. A., \& Wilkerson, E. (2010). Enhancing building, conversation, and learning through caregiver-child interactions in a children's museum. Developmental Psychology, 46, 502-515.

Bjorklund, D. F., Hubertz, M. J., \& Reubens, A. C. (2004). Young children's arithmetic strategies in social context: How parents contribute to children's strategy development while playing games. International Journal of Behavioral Development, 28(4), 347-357.

Bolin, I. (2006). Growing up in a culture of respect: Child rearing in highland Peru. Austin: University of Texas Press.

Bonawitz, E., Fischer, A., \& Schulz, L. (2012). Teaching 3.5-year-olds to revise their beliefs given ambiguous evidence. Journal of Cognition and Development, 13, 266-280.

Bonawitz, E. B., Ferranti, D., Saxe, R., Gopnik, A., Meltzoff, A. N., Woodward, J., \& Schulz, L. E. (2010). Just do it? Investigating the gap between prediction and action in toddlers' causal inferences. Cognition, 115(1), 104-117.

Bonawitz, E. B., van Schijndel, T., Friel, D., \& Schulz, L. (2012). Balancing theories and evidence in children's exploration, explanations, and learning. Cognitive Psychology, 64(4), 215-234.

Bredderman, T. (1983). Effects of activity-based elementary science on student outcomes: A quantitative synthesis. Review of Educational Research, 53, 499-518.

Brewer, W. F., Chinn, C. A., \& Samarapungavan, A. (1998). Explanation in scientists and children. Minds and Machines, 8, 119-136.

Bruner, J. S. (1961). The act of discovery. Harvard Educational Review, $31,21-32$.

Bruner, J. S. (1986). Actual minds, possible worlds. Cambridge: Harvard University Press.

Callanan, M. (2012). Conducting cognitive developmental research in museums: Theoretical issues and practical considerations. Journal of Cognition and Development, 13, 137-151.

Callanan, M., \& Jipson, J. (2001). Explanatory conversations and young children's developing scientific literacy. In K. Crowley, C. Schunn, $\&$ T. Okada (Eds.), Designing for science: Implications for everyday, classroom, and professional settings (pp. 21-49). Mahwah: Erlbaum.

Callanan, M., Martin, J., \& Luce, M. (2016). Two decades of families learning in a children's museum: A partnership of research and exhibit development. In J. Jipson \& D. Sobel (Eds.), Relating research and practice: Cognitive development in museum settings. New York: Psychology Press.

Callanan, M., \& Oakes, L. (1992). Preschoolers' questions and parents' explanations: Causal thinking in everyday activity. Cognitive Development, 7, 213-233.

Callanan, M. A., Shrager, J., \& Moore, J. L. (1995). Parent-child collaborative explanations: Methods of identification and analysis. The Journal of the Learning Sciences, 4, 105-129.

Callanan, M. A., Siegel, D. R., \& Luce, M. R. (2007). Conventionality in family conversations about everyday objects. New Directions for Child and Adolescent Development, 2007(115), 83-97.

Carraher, T. N., Carraher, D. W., \& Schliemann, A. D. (1985). Mathematics in the streets and in schools. British Journal of Developmental Psychology, 3(1), 21-29.

Chi, M. T. H. (2000). Self-explaining expository texts: The dual processes of generating inferences and repairing mental models. In R. Glaser (Ed.), Advances in instructional psychology (pp. 161-238). Hillsdale: Erlbaum.

Chi, M. T., De Leeuw, N., Chiu, M. H., \& LaVancher, C. (1994). Eliciting self-explanations improves understanding. Cognitive Science, 18(3), $439-477$. 
Cimpian, A., \& Petro, G. (2014). Building theory-based concepts: Fouryear-olds preferentially seek explanations for features of kinds. Cognition, 131(2), 300-310.

Clegg, J. M., \& Legare, C. H. (2017). Parents scaffold flexible imitation in early childhood. Journal of Experimental Child Psychology, 153, 1-14.

Clegg, J. M., Wen, N. J., \& Legare, C. H. (2017). Is non-conformity WEIRD? Cultural variation in adults' beliefs about children's competency and conformity. Journal of Experimental Psychology: General, 146(3), 428-441.

Cole, M. (1990). Cognitive development and formal schooling: The evidence from cross-cultural research. In L. C. Moll (Ed.), Vygotsky and education. Cambridge: Cambridge University Press.

Cole, M. (1996). Cultural psychology: A once and future discipline. Cambridge: Harvard University Press.

Cole, M. (2010). Education as an intergenerational process of human learning, teaching, and development. American Psychologist, 65(8), 796-807.

Cook, C., Goodman, N. D., \& Schulz, L. E. (2011). Where science starts: Spontaneous experiments in preschoolers' exploratory play. Cognition, 120, 341-349.

Crowley, K., Callanan, M., Jipson, J., Galco, J., Topping, K., \& Shrager, J. (2001). Shared scientific thinking in everyday parent-child activity. Science Education, 85, 712-732.

Crowley, K., Callanan, M., Tenenbaum, H., \& Allen, E. (2001). Parents explain more often to boys than to girls during shared scientific thinking. Psychological Science, 12, 258-261.

Crowley, K., \& Siegler, R. S. (1999). Explanation and generalization in young children's strategy learning. Child Development, 70, 304-316.

Dean, D., \& Kuhn, D. (2007). Direct instruction vs. discovery: The long view. Science Education, 91, 384-397.

Falk, J., Moussouri, T., \& Coulson, D. (1998). The effect of visitors' agendas on museum learning. Curator, 41, 107-120.

Fender, J., \& Crowley, K. (2007). How parent explanation changes what children learn from everyday scientific thinking. Journal of Applied Developmental Psychology, 28, 189-210.

Fisher, K. R., Hirsh-Pasek, K., Golinkoff, R. M., \& Gryfe, S. G. (2008). Conceptual split? Parents' and experts' perceptions of play in the 21st century. Journal of Applied Developmental Psychology, 29, 305-316.

Fivush, R., Haden, C., \& Reese, E. (2006). Elaborating on elaborations: Role of maternal reminiscing style in cognitive and socioemotional development. Child Development, 77, 1568-1588.

Frazier, B. N., Gelman, S. A., \& Wellman, H. M. (2009). Preschoolers' search for explanatory information within adult-child conversation. Child Development, 80, 1592-1611.

Fung, G., \& Callanan, M. (2013). Pedagogy versus exploration: Parentchild interactions in a museum setting. Poster presented at biennial meetings of Society for Research in Child Development, Seattle, WA.

Gaskins, S. (2008). Designing exhibitions to support families' cultural understandings. Exhibitionist, 27, 10-19.

Gaskins, S., \& Paradise, R. (2010). Learning through observation. In D. F. Lancy, J. Bock, \& S. Gaskins (Eds.), The anthropology of learning in childhood (pp. 85-117). Lanham: Alta Mira Press.

Gauvain, M. (2001). The social context of cognitive development. New York: Guilford Press.

Gauvain, M., Munroe, R. L., \& Beebe, H. (2013). Children's questions in cross-cultural perspective: A four-culture study. Journal of CrossCultural Psychology, 44, 1148-1165.

Gauvain, M., \& Perez, S. (2015). Cognitive development and culture. In R. Lerner (Ed.), Handbook of child psychology and developmental science (7th ed.). New York: Wiley.

Geary, D. C., \& Bjorklund, D. F. (2000). Evolutionary developmental psychology. Child Development, 71(1), 57-65.

Gerson, S., \& Woodward, A. L. (2014). Learning from their own actions: The unique effect of producing actions on infants' action understanding. Child Development, 85, 264-277.
Goodnow, J. J., \& Collins, W. A. (1990). Development according to parents: The nature, sources, and consequences of parents' ideas. New York: Psychology Press.

Gopnik, A. (1998). Explanation as orgasm. Minds and Machines, 8, 101118.

Gutwill, J., \& Allen, S. (2010). Facilitating family group inquiry at science museum exhibits. Science Education, 94, 710-742.

Gweon, H., Pelton, H., Konopka, J. A., \& Schulz, L. E. (2014). Sins of omission: Children selectively explore when teachers are under-informative. Cognition, 132(3), 335-341.

Haden, C. (2010). Talking about science in museums. Child Development Perspectives, 4, 62-67.

Harkness, S., \& Super, C. M. (1996). Parents' cultural belief systems: Their origins, expressions, and consequences. New York: Guilford Press.

Harris, P. L., \& Koenig, M. A. (2006). Trust in testimony: How children learn about science and religion. Child Development, 77(3), 505-524.

Harris, P. L., Pasquini, E. S., Duke, S., Asscher, J. J., \& Pons, F. (2006). Germs and angels: The role of testimony in young children's ontology. Developmental Science, 9(1), 76-96.

Hickling, A. K., \& Wellman, H. M. (2001). The emergence of children's causal explanations and theories: Evidence from everyday conversation. Developmental Psychology, 37(5), 668-683.

Hood, L., \& Bloom, L. (1979). What, when, and how about why: A longitudinal study of early expressions of causality. Monographs of the Society for Research in Child Development, 44(6), 1-47.

Jant, E. A., Haden, C. A., Uttal, D. H., \& Babcock, E. (2014). Conversation and object manipulation influence children's learning in a museum. Child Development, 85, 2029-2045.

Jara-Ettinger, J., Gweon, H., Tenenbaum, J. B., \& Schulz, L. E. (2015). Children's understanding of the costs and rewards underlying rational action. Cognition, 140, 14-23.

Keil, F. (2006). Explanation and understanding. Annual Review of Psychology, 57, 227-254.

Keil, F. C., \& Wilson, R. A. (2000). Explanation and Cognition. MIT Press.

Keller, H. (2007). Cultures of infancy. Mahwah: Erlbaum.

Keller, H., Voelker, S., \& Yovsi, R. D. (2005). Conceptions of parenting in different cultural communities: The case of West African Nso and Northern German women. Social Development, 14(1), 158-180.

Kittel, J. E. (1957). An experimental study of the effect of external direction during learning on transfer and retention of principles. Journal of Educational Psychology, 48, 391-405.

Klahr, D., \& Nigam, M. (2004). The equivalence of learning paths in early science instruction: Effects of direct instruction and discovery learning. Psychological Science, 15, 661-667.

Kushnir, T., \& Gopnik, A. (2005). Young children infer causal strength from probabilities and interventions. Psychological Science, 16(9), 678-683.

Lagnado, D. A., \& Sloman, S. (2004). The advantage of timely intervention. Journal of Experimental Psychology Learning Memory and Cognition, 30, 856-876.

Lancy, D. (2008). The anthropology of childhood: Cherubs, chattel, changelings. Cambridge: Cambridge University Press.

Lancy, D. F., Bock, J. C., \& Gaskins, S. (2010). The anthropology of learning in childhood. New York: Rowman \& Littlefield.

Lave, J., \& Wenger, E. (1991). Situated learning: Legitimate peripheral participation. Cambridge: Cambridge University Press.

Legare, C. H. (2012). Exploring explanation: Explaining inconsistent information guides hypothesis-testing behavior in young children. Child Development, 83, 173-185.

Legare, C. H. (2014). The contributions of explanation and exploration to children's scientific reasoning. Child Development Perspectives, $8(2), 101-106$

Legare, C. H., \& Gelman, S. A. (2014). Examining explanatory biases in young children's biological reasoning. Journal of Cognition and Development, 15, 287-303. 
Legare, C. H., Gelman, S. A., \& Wellman, H. M. (2010). Inconsistency with prior knowledge triggers children's causal explanatory reasoning. Child Development, 81, 929-944.

Legare, C. H., Gose, R., \& Guess, C. (2016). Examining the development of scientific reasoning in context: A museum and laboratory partnership. In J. Jipson \& D. Sobel (Eds.), Relating research and practice: Cognitive development in museum settings (pp. 139-148). New York: Psychology Press.

Legare, C. H., \& Harris, P. L. (2016). The ontogeny of cultural learning. Child Development, 87(3), 633-642. doi:10.1111/cdev.12542

Legare, C. H., \& Lombrozo, T. (2014). Selective effects of explanation on learning during early childhood. Journal of Experimental Child Psychology, 126, 198-212.

Legare, C. H., Wellman, H. M., \& Gelman, S. A. (2009). Evidence for an explanation advantage in naïve biological reasoning. Cognitive Psychology, 58, 177-194.

Luce, M., Callanan, M., \& Smilovic, S. (2013). Links between parents' epistemological stance and children's evidence talk. Developmental Psychology, 49, 454-461.

Mayer, R. E. (2004). Should there be a three-strikes rule against pure discovery learning? The case for guided methods of instruction. American Psychologist, 59, 14-19.

Needham, A. (2009). Learning in infants' object perception, objectdirected action, and tool use. In A. Needham \& A. Woodward (Eds.), Learning and the infant mind (pp. 208-226). New York: Oxford University Press.

Nielsen, M., Haun, D., Kärtner, J., \& Legare, C. H. (2017). The persistent sampling bias in developmental psychology: A call to action. Journal of Experimental Child Psychology. doi:10.1016/j.jecp. 2017.04.017

Okagaki, L., \& Divecha, D. J. (1993). Development of parental beliefs. In T. Luster \& L. Okagaki (Eds.), Parenting: An ecological perspective (pp. 35-67). Hillsdale: Erlbaum.

Rittle-Johnson, B., Saylor, M., \& Swygert, K. E. (2008). Learning from explaining: Does it matter if mom is listening? Journal of Experimental Child Psychology, 100, 215-224.

Rogoff, B. (1990). Apprenticeship in thinking: Cognitive development in social context. Oxford: Oxford University Press.

Rogoff, B. (2003). The cultural nature of human development. Oxford: Oxford University Press.

Schauble, L. (1996). The development of scientific reasoning in knowledge-rich contexts. Developmental Psychology, 32, 102-119.

Schulz, L. E., \& Bonawitz, E. (2007). Serious fun: Preschoolers play more when evidence is confounded. Developmental Psychology, 43, 1045-1050.

Schulz, L. E., Gopnik, A., \& Glymour, C. (2007). Preschool children learn about causal structure from conditional interventions. Developmental Science, 10, 322-332.

Shulman, L., \& Keislar, E. (1968). Learning by discovery: A critical appraisal. Chicago: Rand McNally.

Silva, K. G., Correa-Chávez, M., \& Rogoff, B. (2010). Mexican heritage children's attention and learning from interactions directed to others. Child Development, 81(3), 898-912.

Singer, D., Golinkoff, R. M., \& Hirsh-Pasek, K. (Eds.). (2006). Play=Learning: How play motivates and enhances children's cognitive and social-emotional growth. New York: Oxford University Press.

Sobel, D. (2004). Place-based education: Connecting classroom and community. Barrington: The Orion Society.

Sobel, D., \& Jipson, J. (2016). Relating research and practice: Cognitive development in museum settings. New York: Routledge.

Sobel, D. M., \& Kushnir, T. (2006). The importance of decision making in causal learning from interventions. Memory \& Cognition, 34, $411-419$.
Sobel, D. M., Letourneau, S. M., \& Meisner, R. (2016). Developing Mind Lab: A university-museum partnership to explore the process of learning. In J. Jipson \& D. Sobel (Eds.), Relating research and practice: Cognitive development in museum settings (pp. 120137). New York: Psychology Press.

Sobel, D. M., \& Sommerville, J. A. (2009). Rationales in children's causal learning from others' actions. Cognitive Development, 24(1), 70-79.

Sobel, D. M., \& Sommerville, J. A. (2010). The importance of discovery in children's causal learning from interventions. Frontiers in Developmental Psychology, 1, 176-183.

Solis, G., \& Callanan, M. (2016). Evidence against deficit accounts: Conversations about science in Mexican-heritage families living in the US. Mind, Culture, and Activity, 23, 212-224.

Sommerville, J. A., Woodward, A. L., \& Needham, A. (2005). Action experience alters 3-month-old infants' perception of others' actions. Cognition, 96, B1-B11.

Stahl, A. E., \& Feigenson, L. (2015). Observing the unexpected enhances infants' learning and exploration. Science, 348, 91-94.

Tare, M., French, J., Frazier, B., Diamond, J., \& Evans, E. M. (2011). Explanatory parent-child conversation predominates in an evolution exhibit. Science Education, 95, 720-744.

Tenenbaum, H., \& Callanan, M. A. (2008). Parents' science talk to their children in Mexican descent families residing in the USA. International Journal of Behavioral Development, 32, 1-12.

Tizard, B., Hughes, M., Carmichael, H., \& Pinkerton, G. (1983). Children's questions and adults' answers. Journal of Child Psychology and Psychiatry, 24, 269-281.

Tudge, J. R. H., Putnam, S. E., \& Valsiner, J. (1991). Culture and cognition in developmental perspective: Reading as a co-constructive process. Greensboro: Unpublished manuscript, University of North Carolina.

Valle, A. (2006). "How do you know?" Communicating ideas about science and scientific reasoning in parent-child conversations (Unpublished doctoral dissertation). University of California, Santa Cruz.

Van Schijndel, T. J. P., Franse, R. K., \& Raijmakers, M. E. J. (2010). The exploratory behavior scale: Assessing young visitors' hands-on behavior in science museums. Science Education, 94, 794-809.

Vygotsky, L. S. (1962). Thought and language. Cambridge: MIT Press.

Walker, C. M., Lombrozo, T., Legare, C. H., \& Gopnik, A. (2014). Explaining prompts children to privilege inductively rich properties. Cognition, 133, 343-357.

Walker, C. M., Lombrozo, T., Williams, J. J., Rafferty, A., \& Gopnik, A. (2017). Explaining constrains causal learning in childhood. Child Development, 88, 229-246.

Weisberg, D. S., Hirsh-Pasek, K., \& Golinkoff, G. (2013). Guided play: Where curricular goals meet a playful pedagogy. Mind, Brain, \& Education, 7, 104-112.

Weisberg, D. S., Hirsh-Pasek, K., Golinkoff, R. M., Kittredge, A. K., \& Klahr, D. (2016). Guided play: Principles and practices. Current Directions in Psychological Science, 25(3), 177-182.

Wellman, H. M. (2011). Reinvigorating explanations for the study of early cognitive development. Child Development Perspectives, 5, 33-38.

Wellman, H. M., \& Liu, D. (2007). Causal reasoning as informed by the early development of explanations. In A. Gopnik \& L. Schulz (Eds.), Causal learning: Psychology, philosophy, and computation (pp. 261-279). Oxford: Oxford University Press.

Wertsch, J. V., \& Tulviste, P. (1992). L. S. Vygotsky and contemporary developmental psychology. Developmental Psychology, 28(4), 548557.

Xu, F., \& Kushnir, T. (2012). Advances in child development and behavior: Rational constructivism in cognitive development. Waltham: Elsevier. 